\title{
The effect of arousal on Stroop color-word task performance
}

\author{
MICHAEL S. PALLAK, THANE S. PITTMAN, JACK F. HELLER, and PAUL MUNSON \\ University of Iowa, Iowa City, Iowa 52240
}

\begin{abstract}
In two experiments, performance on a modified version of the Stroop color-word task varied systematically with level of task-irrelevant arousal. Performance under low response competition was facilitated while performance under high response competition was impaired by arousal manipulated via threat of impending electric shock. The present results were thus consistent with traditional theory relating arousal or drive and response competition and suggest that Stroop task performance may thereby provide a behavioral index of arousal level.
\end{abstract}

While performance on the Stroop color-word task (Stroop, 1935) has been widely used as a index of various individual differences (cf. Jensen \& Rohwer, 1966), recently Hochman $(1967,1969)$ and Pallak and Pittman (1972) suggested that performance on a modified version of the task may also provide an index of arousal level. For example, within traditional learning theory, motivational constructs such as drive facilitate responses both instrumental and noninstrumental to reduction of drive level (cf. Hull, 1943; Spence \& Spence, 1966). In task situations in which habit strength of the correct response is dominant or has a high probability of emission, an increment in drive level facilitates the response and thereby enhances task performance. However, in task situations in which habit strength of the correct response is low, that is, where habit strength of an incorrect response is high, an increment in drive level facilitates the competing response and thereby diminishes successful task performance (cf. Spence \& Spence, 1966).

Hochman's $(1967,1969)$ version of the Stroop task varied verbal response competition by serially presenting a list of nouns printed in various colors of ink and requiring the subject to name the color of the ink. In the high response competition conditions, the nouns employed named competing colors. In the low response competition conditions, the nouns employed had no strong color associations. Stress or arousal was manipulated by varying the length of response time permitted for the subject to name the color of the ink for each noun-ink color stimulus item. Subjects in the high arousal condition were allowed $1 \mathrm{sec}$, while subjects in the low arousal condition were allowed $2 \mathrm{sec}$ to

This research was supported in part by a faculty research grant to the first author awarded by the Graduate College (University of Iowa) from National Institutes of Health Biomedical Sciences Research Program funds and in part by traineeships to the second and third authors from National Institutes of Health Training Grant funds in the area of social psychology. The second, third, and fourth authors are now at Getty sburg College, Franklin and Marshall College, and University of Kansas, respectively. This paper was sponsored by Rudolph W. Schulz who takes full editorial responsibility. respond to each presentation. Hochman $(1967,1969)$ found that high stress resulted in more verbal errors in the high response competition version but failed to find that high stress resulted in fewer errors under low response competition relative to performance in the low stress conditions. While the results partially support Hochman's (1967, 1969) interpretation of the Stroop task as an index of arousal, both the absence of facilitation of performance under low response competition and the fact that elements of the task served as both a source of stress or arousal and of response competition render the implications of these studies somewhat ambiguous.

However, the Stroop color-word task is a potentially convenient and useful performance index of arousal or drive. For example, the instructions and procedure employed in the present research took only a few minutes (and closely followed that of Hochman, 1967, 1969). A satifactory demonstration of Hochman's point that Stroop task performance may index arousal or drive level could be achieved by showing that performance varied as a function of arousal unrelated to the task (and thus Stroop task performance would be noninstrumental to reduction of arousal) such that subjects under high arousal made a larger number of errors under the high response competition and fewer errors under the low response competition versions of the task.

\section{EXPERIMENT I}

\section{Method}

Subjects. A total of 46 female introductory psychology students participated individually for course credit and were randomly assigned to condition in a 2 by 2 factorial design (high vs. Low response competition by threat of shock vs. no threat of shock).

Materials and apparatus. In all cases, stimulus items were printed in red, blue, or green ink. In the high response competition list, stimulus nouns employed were "red," "blue," or "green," and ink and noun were always paired incongruously (i.e., the noun "red" printed in blue ink). In the low response competition list, the stimulus items employed were "lot," "safe," and "close" printed in the same order of ink color as in the high response competition list (thus the number and order of ink colors were identical for both response competition 
Table 1

Mean Number of Errors as a Function of Level of Response Competition and Threat of Shock: Experiment I

\begin{tabular}{lcc}
\hline & \multicolumn{2}{c}{ List } \\
\cline { 2 - 3 } & $\begin{array}{c}\text { High } \\
\text { Competition }\end{array}$ & $\begin{array}{c}\text { Low } \\
\text { Competition }\end{array}$ \\
\hline Threat of Shock & 14.18 & 2.36 \\
$\mathrm{~N}$ & 11 & 11 \\
No Threat of Shock & 7.92 & 3.42 \\
$\mathrm{~N}$ & 12 & 12 \\
\hline
\end{tabular}

conditions). In all cases, the subject was required to verbalize the color of the ink in which stimulus items were printed, and subjects received a list of 90 items presented at the rate of one item per second via a Stowe memory drum. All responses were tape-recorded and scored subsequently for errors such as incorrect color responses, noun reading, omitted responses, or contaminated responses (e.g., "gred" in response to the noun "green" printed in red ink). In all cases, the scorer employed was not the experimenter for the particular subject and was blind as to threat of shock condition, thereby minimizing bias effects.

Procedure. Following 10 practice trials (items), all subjects were told that they would actually participate in two unrelated experiments, the first involving verbal task performance (the Stroop task), and the second involving motor task performance. In the no threat of shock conditions, subjects were told that immediately following the verbal task study, they would be in a study involving motor tasks which they would find "fairly simple and somewhat enjoyable." In the threat of shock conditions, subjects received the same motor task description and were also told that they would receive painful electric shock while performing the motor tasks: "Of course, these shocks won't burn you or cause any permanent damage, but they will be painful." All subjects then responded to 90 Stroop color-word items (either high or low response competition), filled out a questionnaire, and were debriefed; and no subjects participated in the ficticious second motor-task study.

\section{Results}

Self-report measures indicated that threat of shock subjects reported considerably more anxiety about being in the "second" experiment than no threat subjects, $F(1,42)=15.64, p<.001$. There were no differences in self-reports of how hard subjects worked at the Stroop task, suggesting that subjects voluntary efforts at the task did not differ. An analysis of errors from the 10 practice trials indicated that high response competition subjects made more errors than low response competition subjects, $F(1,42)=6.63, p<.05$, as expected.

Analysis of the major dependent variable, number of errors over the 90 test trials (presented in Table 1) indicated more errors in the high response competition condition than in the low response competition condition, $F(1,42)=25.25, p<.001$, as expected, and a Threat of Shock by Response Competition interaction, $F(1,42)=7.74, p<.01$. Planned comparisons (cf. Winer, $1971)$ indicated that under high response competition, subjects in the threat of shock condition made more errors than subjects in the no threat of shock condition, $\mathrm{F}(1,42)=5.27, \mathrm{p}<.05$. Under low response competition, while subjects under threat of shock made fewer errors than subjects under no threat of shock, this difference was not statistically reliable. However, inspection of the raw data suggested that since subjects under low response competition made few errors in general, the absence of threat of shock effect may have represented a "floor" effect. The second experiment below was designed to minimize the possibility by deleting the 10 practice trials from the procedure in order to demonstrate facilitation of task performance by threat of shock under low response competition.

\section{EXPERIMENT II}

\section{Method}

A total of 21 female introductory psychology students participated individually for class credit and were randomly assigned to either the threat of shock or the no threat of shock condition under low competition only. In all respects other than deletion of the 10 practice trials, the procedure for the second experiment was identical to that of the first experiment.

\section{Results}

Self-report measures indicated that subjects under threat of shock were more anxious about "second" experiment, $t(19)=1.87, p<.10$, in the threat of shock condition, and were less eager to participate in the "second" experiment, $\mathrm{t}(19)=4.638, \mathrm{p}<.01$, than subjects under no threat of shock, as expected.

Analysis of the total error during the 90 test trials (Table 2) indicated that threat of shock subjects made fewer errors than no threat of shock subjects, $t(19)=2.10, p<.05$, as predicted (see Table 2 ).

\section{DISCUSSION}

Taken together, the results from the present experiments suggest that level of arousal and level of response competition for the Stroop color-word task interactively determine Stroop color-word task performance and that this interaction is consistent with more traditional motivational results within learning theory (cf. Spence \& Spence, 1966). The results from the second experiment suggest that practice trials may reduce error rates on the Stroop task presumably by increasing the habit strength of the correct response, i.e., in the present case, that of verbalizing the ink color. Presumably the practice trials thus eliminated whatever competing response tendencies may have been present under low response competition and thereby produced the apparent "floor" effect obtained under low response competition in the first experiment. Thus the present results are consistent with Hochman's $(1967,1969)$ line of reasoning and suggest that Stroop task performance may provide a reliable and efficient behavioral index of psychological tension

Table 2

Mean Number of Errors on the Low Competition List as a Function of Threat of Shock: Experiment II

$\begin{array}{lc}\text { Threat of Shock } & 1.73 \\ \mathrm{~N} & 11 \\ \text { No Threat of Shock } & 4.60 \\ \mathrm{~N} & 10\end{array}$


or general motivation. We might note that the present results are also consistent with previous research relating level of arousal and response competition manipulated via intralist response competition varied by semantic associations between stimulus and response items in paired associate acquisitions (Spence, Farber, \& McFann, 1954; cf. Spence \& Spence, 1966).

\section{REFERENCES}

Hochman, S. H. The effects of stress on Stroop color-word performance. Psy chonomic Science, 1967, 9, 475-476.

Hochman, S. H. Stress and response competition in children's color-word performance. Perceptual and Motor Skills, 1969, 28, 115-118.

Hull, C. L. Principles of behavior. New York: Appleton-Century-Crofts, 1943.

Jensen, A. R., \& Rohwer, W. D. The Stroop color-word test: A review. Acta Psychologica, 1966, 25, 36-93.
Pallak, M. S., \& Pittman, T. S. General motivational effects of dissonance arousal. Journal of Personality \& Social Psychology, 1972, $21,349-358$.

$\begin{aligned} & \text { gy, } 1972,21,349-358 . \\ & \text { Spence, J. T., \& Spence, } K \text {. W. The motivational components of }\end{aligned}$ manifest anxiety: Drive and drive stimuli. In C. D. Spielberger (Ed.), Anxiety and behavior. New York: Academic Press, 1966.

Spence, K. W., Farber, I. E., \& McFann, H. H. The relation of anxiety (drive) level to performance in competitional paired-associates learning. Journal of Experimental Psychology, 1956, 52, 296-305.

Stroop, J. R. Studies of interference in serial verbal reactions. Journal of Experimental Psy chology, 1935, 18, 643-662.

Winer, B. J. Statistical principles in experimental design. New York: McGraw-Hill, 1971.

(Received for publication March 7, 1975.) 